\title{
Errata: Thermal, structural, and optical properties of Cleartran $®$ multispectral zinc sulfide
}

\author{
Daniel C. Harris \\ Meghan Baronowski \\ Naval Air Systems Command \\ 1900 N. Knox Road, Stop 6303 \\ China Lake, California 93555 \\ E-mail: Daniel.Harris@ navy.mil \\ Ladd Henneman \\ Len LaCroix \\ Clyde Wilson \\ Shelby Kurzius \\ Lockheed Martin Space Systems Company \\ 1111 Lockheed Martin Way \\ Sunnyvale, California 94089
}

\section{Bob Burns}

Vicus Technologies

86 York St, Suite 1

Kennebunk, Maine 04043

\section{Keith Kitagawa}

Pacific Optical Division of Recon/Optical

1190 Columbia Avenue

Riverside, California 92507

\section{Jozef Gembarovic}

TPRL, Inc.

3080 Kent Avenue

West Lafayette, Indiana 47906

\section{Steven M. Goodrich}

University of Dayton Research Institute

300 College Park

Dayton, Ohio 45469

\section{Christian Staats}

Schmitt Industries

2765 NW Nicolai Street

Portland, Oregon 97210

John J. Mecholsky, Jr.

University of Florida

Materials Science \& Engineering Department

Gainesville, Florida 32611

This article [Opt. Eng. 47, 114001 (2008)] was originally published on 6 November 2008 with errors in Eq. (20). A negative sign was missing in the numerator and an addition sign appeared in the denominator instead of a minus sign. The correct equation is as follows:

$t=\frac{(1-R)^{2} \exp \left(-\alpha b / \cos \theta_{\mathrm{r}}\right)}{1-R^{2} \exp \left(-2 \alpha b / \cos \theta_{\mathrm{r}}\right)}$,

All online versions of the article were corrected on 23 July 2009. 